\title{
Age, Ethnicity and Equalities: Synthesising Policy and Practice Messages from Two Recent Studies of Elder Abuse in the UK
}

\author{
Jill Manthorpe* and Alison Bowes** \\ *Social Care Workforce Research Unit, King's College London \\ E-mail: jill.manthorpe@kcl.ac.uk \\ **Department of Applied Social Science, University of Stirling
}

Two recent studies of elder abuse in the UK are located in current policy contexts of adult safeguarding. After describing the studies, the discussion draws out their central messages and identifies the challenges that the studies present to recent policy debates and innovations. These relate to the need to properly integrate both wider older people's issues and issues of racism and ethnicity within developments in adult safeguarding policy as well as social care services as the personalisation agenda advances.

\section{Introduction}

This paper draws on comparative discussion of two important studies of elder abuse in the UK. It outlines the background to the studies, locating them in current policy contexts of adult safeguarding. Following a brief description of the studies' origins and methods, we draw out the central messages from each relating to ethnicity and elder abuse, noting their commonalities and differences. We then outline some of the challenges that these messages have in current policy contexts and the choices that face policy makers when responding to the studies' findings. The paper concludes with some observations about the potential for research about elder abuse among different ethnic groups to contribute to policy improvement and thus to prevention, response and good outcomes.

\section{Background}

Patterson and Malley-Morrison (2006) have maintained that older people are universally susceptible to abuse, and that this can be explained by several individual and social factors. Elder abuse among people from black and minority ethic (BME) groups in Western societies is a complex issue with five key currents. First, notions about the appropriate 'treatment' of older people vary cross-culturally, and notions of 'mistreatment' are therefore also likely to vary. Second, the general difficulties experienced by professionals in tackling elder abuse may be compounded since services and interventions lack capacity, skill and confidence in their responses to ethnic diversities (Butt and Mirza, 1996; Bowes and Dar, 2000). Third, family structures and communities are ethnically diverse, and the context of and explanations for abuse are likely to vary. Fourth, people from BME communities may experience additional exclusion through racism, which may compound the effects of ageism. Finally, older people from BME backgrounds are diverse and the impacts of migration, language, culture, age cohort, socio-economic 
status and social networks expose their heterogeneity (Iliffe and Manthorpe, 2004). These complexities may create variations in the form that elder abuse and neglect may take and its interpretations.

However, relatively little attention has been paid to elder abuse in BME communities, again for several possible reasons. Blakemore and Boneham (1994: 83) made only passing reference to possible abuse in isolated Asian families; Biggs et al. (1995) referred to racism as an additional form of elder abuse, and note that migration may disturb family relationships and traditions, and, more speculatively, may increase the possibility of abuse. Similarly, Slater and Eastman's (1999) discussion of elder abuse and responses to it did not address minority issues or possible cultural variation. Scott (1998) maintained that elder abuse is an issue for BME communities and discussed how some of the relevant cultural and other factors might come into play. As Bowes et al. (2008) argued, there is a perception that for BME communities, experiences of, explanations for and service responses to elder abuse may differ from those currently available. These differences are partly to do with experiences of BME groups themselves, their particular cultural beliefs and family structures, but they are also related to wider social processes and practices, including racism, the marginalisation of minority groups and the limited ways in which practitioners and service providers have responded to diversity.

Internationally, researchers have been exploring elder abuse and cultural issues for far longer than in the UK, taking account of different cultural perspectives and experiences. Yan and Tang (2003), for example, analysed the literature on elder abuse in Chinese communities and linked increasing abuse with a breakdown in traditional values of filial piety. Tsukada et al. (2001) examined knowledge and perceptions of elder abuse among Japanese older people. Others have examined familial abuse more generally, highlighting the interaction of culturally specific issues with experiences of exclusion (e.g. Harvie, 1991; Samad and Eade, 2003). However, there is debate concerning how far particular cultural factors affect experiences and understandings of elder abuse. Whereas some researchers detect connections between particular cultural ideals and particular experiences of abuse, others have concluded that the central influences are poverty and marginalisation of older people.

\section{The diversity of the UK older population}

From a public policy perspective, considering both prevention and responses, the UK demographic profile is changing. Currently, 16 per cent are aged 65 years and over, of whom 9 per cent are of black Caribbean origin, and 6 per cent of Asian Indian origin (Office for National Statistics, 2002). The largest predicted increases are among older BME people. By 2026, it is estimated that the number of older BME people in the UK will have risen tenfold, from 175,000 to over 1.8 million. Within this, there are wide local variations: for example, in London over 30 per cent of older people in the Borough of Brent and 20 per cent in Lambeth and Hackney are from BME backgrounds (Lowdell et al., 2000). Moreover, there are differences between ethnic groups in patterns of ageing, with some groups much better off than others in terms of financial resources and health status (Bajekal et al., 2004). This growing diversity among people from BME communities reflects the great diversity among all older people (Moriarty and Butt, 2004). 
Overall, numbers of older people from BME groups are likely to rise (Katbamna and Matthews, 2006) but unevenly. Harris et al. (2008) considered some of the local implications, including:

- People may continue to move out of inner cities, especially London, in retirement (Catney and Simpson, 2009), so other localities will need to develop greater competence in working with BME older people. Family networks may be less close knit and community networks less familiar.

- Major changes in groups' composition are emerging as more recent arrivals to the UK have different origins to those who arrived in the period 1960-1980. For example, new community languages will require a greater range of interpreters (e.g. Pashtun, Somali or Arabic) and links with different faith and cultural groups.

- In some urban areas of England, BME communities are not 'minority' populations and this will be increasingly reflected in older populations. The implications of this move from numerical minority to majority are unknown. Some UK cities will become super-diverse or plural cities in which no one ethnic group comprises the majority and 'where the country's immigrant and ethnic community can no longer be characterised by large, well organised African-Caribbean and South Asian communities' (Barrow Cadbury Trust, 2007: 2).

- Socio-demographic variations mean that, while there may be pockets of affluence, many BME older people face poverty in retirement, particularly those from Pakistani and Bangladeshi communities (PRIAE, 2005). Further, some BME groups are more likely to be in poor health in later life, particularly South Asian communities (DH, 2001).

The implications for adult safeguarding (the term used in the UK to respond to elder abuse and other abuse and neglect of 'vulnerable' adults) of these factors and changes are multilevel. The next section considers the scope of two studies that took place at the same time and are potentially 'mutually informative'.

\section{Studies' scope}

Surprisingly few analyses across research in the area of elder abuse, or other areas, take an in-depth comparative approach. There are, of course, many overviews of research; indeed the subject of elder abuse in the UK was for many years dominated by 'overviews of overviews' (Manthorpe et al., 2005) in the general absence of research. The present paper considers two studies relating to elder abuse and explores issues regarding ethnicity emerging from them. One study took age and ethnicity as its particular focus (Bowes et al., 2008); the other did not, but aimed nevertheless to be inclusive and recognised the potential importance of ethnicity and diversity among study participants and the contexts of their care and support (Mowlam et al., 2007; O'Keefe et al., 2007). Bringing together and learning from the process of the studies and their findings have the potential, we suggest, to make more of the 'sum of their parts'.

The two studies took place during the same period. The UK study of abuse and neglect of older people (National Elder Abuse Study - NEAS), funded by the charity Comic Relief and the Department of Health $(\mathrm{DoH})$, sought nationally representative prevalence estimates of elder abuse and neglect (O'Keefe et al., 2007). As with many such studies, an advisory group of older people was set up to assist the research team. This group of 
12 individuals advised on communications, ethics, research tools and approaches and debated findings as they emerged. Three members were from BME backgrounds and they further assisted with preparatory stages by putting the research team in touch with BME groups. One group, for example, meeting in a lunch club, debated possible ways of talking about mistreatment and managing discussion about other wider difficulties. Preparation for this survey was extensive (see McCreadie et al., 2006) and further discussions with individual BME older people helped refine the survey, particularly establishing if people from diverse backgrounds were able to understand the meaning of questions and processes of informed consent.

Following the preparatory stages, 2,111 face-to-face interviews were carried out with individuals aged 66 and over, living in private households (including sheltered accommodation) in the UK between March and September 2006. The survey was extended by a qualitative study involving follow-up interviews with 36 survey participants who had disclosed abuse and were willing to be interviewed further, and three interviews with older people accessed through BME organisations who had such experiences and were willing to be interviewed (Mowlam et al., 2007: i). These in-depth interviews discussed specific experiences of abuse and mistreatment, and people's decisions about seeking help or modifying the impact or risks. The reasons for recruiting further participants in the qualitative study from BME backgrounds using a different route were, firstly, that the survey did not recruit people who did not speak English; and, secondly, that there turned out to be no BME participants among the volunteer sample for interviewing. Information was supplied to staff in voluntary sector organisations to pass to BME older people whom they knew or suspected of being mistreated or neglected. If individuals agreed, their contact details were passed to the researchers. In two instances, interviews were arranged and conducted through group workers owing to the difficulty of making arrangements where individuals did not communicate in English (Mowlam et al., 2007: 18), acknowledging the difficulties that this may encounter in translation and analysis.

Briefly, those interviewed reported valuing help from community organisations which they contacted about any difficulties, including mistreatment and abuse. Their use of other agencies was restricted because they were not always aware of their scope and were uncertain of their confidentiality policies. They felt that community organisations understood their culture, and for some this was particularly important for language reasons (Mowlam et al., 2007: 51).

The second study addressed a significant gap in knowledge concerning the perceptions and experiences of elder abuse in BME communities in the UK (Bowes et al., 2008). Funded by the Big Lottery Fund, with the University of Stirling being the research partner of Age Concern Scotland, it considered the implications of these perceptions and experiences for service responses to elder abuse. A UK-wide audit of available services was conducted to identify examples of good practice, in which a sensitive response to elder abuse takes account of cultural diversity. The study explored the perceptions of BME people themselves about elder abuse, interviewing 58 people from BME communities in depth. Participants included a wide range of ethnic origins, representing the broad categories of African Caribbean, Chinese, South Asian and White European (e.g. Polish, Jewish, Italian) minorities. Finally, a series of focus groups involving 56 people examined the 'fit' or lack of it between the service providers' ideas about good practice and those of their potential clients. The focus was very much 'on the ground' and at the community and service front line. 
All the service providers interviewed agreed that mistreatment of older people was an issue in BME communities. They perceived good services for BME communities to be those that had good connections with local BME communities, cultural competence and involvement in multi-agency working. They noted their scarcity, and that many service providers faced challenges, including the persistence of a 'colour-blind' approach to service provision, whereby services were assumed to be appropriate for all; funding and resourcing problems, especially for the BME voluntary sector; and the need to continue building links with BME community organisations. Throughout, service providers tended to emphasise mistreatment within families and only a minority considered mistreatment by services or wider society. They also used 'official' language, such as that referring to categories of abuse, and most were familiar with adult safeguarding developments. However, there were limited connections between the BME voluntary sector, despite its significant service delivery role, and statutory adult safeguarding services.

Interviews with community members revealed a common perception that older people are not treated well in today's society, both within families and more widely. Older people in BME communities were perceived to be experiencing mistreatment and two thirds of respondents knew of specific examples, which had occurred within families and outside. The most common type of mistreatment identified was lack of 'respect', named by three quarters of respondents. These views and experiences differed very little between ethnic categories. A wide range of reasons given for mistreatment of older people included difficulties in families, pressure on carers and the position of older people in society, with the most likely abusers said to be family members and care workers.

Forty-six people said that an older person from a BME community experiencing mistreatment would 'do nothing' about it. Reasons for this included cultural factors, shame, dependency, fear, lack of alternatives and wider social exclusion, referring to people's own traditions as well as the pressures of social context. Although doing nothing was seen as the most likely response, if help was sought outside the family it was thought most likely to be sought from the BME voluntary sector, perceived as able to respond more effectively than statutory services.

\section{Main policy messages}

The Secretary of State for Health (2004) in his response to the House of Commons Select Committee Inquiry into elder abuse made an early policy commitment to this area:

The Government will identify the extent to which current organisations that offer support and advice to vulnerable adults and others with respect to abuse have geared themselves to meeting the needs of minority ethnic communities. If there is a shortfall, the Government will consider, with stakeholders, an appropriate course of action. (Secretary of State for Health, 2004: 19)

It is difficult to say that either study reported here has impacted on policy or practice, However, both were cited as background to the DoH review of the multi-agency guidance on adult safeguarding in England, with Bowes et al. (2008) being the only study mentioned in the area of ethnicity:

We may also need to look at safeguarding issues from an equalities perspective. A recent study by Age Concern Scotland reported that $80 \%$ of older people from black and ethnic 
minority (BME) backgrounds who were consulted said they would do nothing if they were being mistreated. The issues involved in not reporting harm need to be looked at in culturally sensitive ways, and the BME voluntary sector and advocacy groups have important roles to play. (DoH, 2008: 7)

This led to particular efforts in the consultation to obtain views of people from BME groups through the commissioning of special events and discussion groups to consider the questions raised by the review. At the time of writing (June 2009), the government response to the consultation is awaited.

Likewise, NEAS was also cited in the review as providing part of the evidence that justified the review. NEAS had itself origins in the call from the Health Select Committee inquiry into elder abuse that more needed to be done to answer some basic questions about incidence and prevalence (House of Commons, 2004).

The NEAS findings set out more than just these bare estimates, useful as they are for professionals and agencies making use of them to develop services and to command resources (Manthorpe et al., 2008). For example, it alerted wider agencies, such as the police and community safety partnerships, about potential risk situations, notably the vulnerability of older men living alone. In particular, the NEAS survey pointed to the risks faced by disabled older people being cared for by their partners and the ways in which this situation might lead unintentionally to poor quality care and neglect as the carer partner found their responsibilities increasingly difficult and perceived, rightly or wrongly, services to be inaccessible or inappropriate. Links between carers' organisations and groups with a focus on elder abuse have not always been strong and this point has provided both with an opportunity to rebuild connections.

Thus, while a focus on national data can be helpful, and can inform national developments, the NEAS survey exposed local diversity and variations, within and across the four nations of the UK, presenting national, regional and local interest groups with national prevalence figures that could be applied to local populations. This may be helpful at several levels and needs to interweave with findings related to local populations. The research team argued that localities can compile and debate figures that have some meaning to local populations yet are backed up by a robust national study (Manthorpe et al., 2008), answering the perennial questions of policy makers, politicians, and commissioners about whether this is a matter with which they should be concerned. Such local calculations might usefully be applied to estimating the resources necessary to respond to the needs of people who are at risk or have been affected in any locality. The NEAS study provided evidence that support for people who are labelled as 'perpetrators' is needed in a preventative sense because risks of abuse and neglect may be reduced though service development, capacity building and investment. As mentioned above, the study's identification of situations of neglect that involved partners/spouses with disabilities who may be increasingly failing to provide adequate care raised questions about the scale of support available to older people and the ways in which such couples might be assisted to access help. In England and Scotland, new forms of social care provision, involving personalisation and self-directed support, are emerging to meet the policy goal of early intervention and prevention (DoH, 2007) and it may be timely for prevention and safeguarding to be linked, rather than prevention being cast as a way of avoiding 
unnecessary hospital admission and so on. This will necessitate new ways of thinking about how to address mistreatment of all older people in both policy and practice.

There have been few attempts to link prevention of ill health with prevention of elder abuse, implicit as safety and well-being may be for physical and mental wellness, still less in the area of ethnic and cultural diversity. Watson (2008) argued that prevention is a process of effective listening and communication - advocating, educating and guiding individuals and communities and she portrayed cultural sensitivity as being 'at the heart of providing effective prevention strategies within the minority ethnic populations'. New research by Bowes and colleagues, funded again by the DoH and Comic Relief, may help unravel some of these complexities in care homes for older people, both those specifically geared towards BME residents and those which provide services to people from a range of backgrounds.

\section{Discussion}

To address the needs of older people from BME communities for safeguarding and social inclusion, amongst others, public sector organisations must meet part of the requirements of the Race Relations (Amendment) Act 2000, which place a duty on public authorities to promote equality of opportunity for people of different racial backgrounds. This entails developing strategic approaches to meeting the needs of BME older people, whether this is done separately or through crosscutting themes. The capacity of safeguarding systems to support BME older people is, therefore, not simply a matter of good practice but has a legal mandate.

Similarly, there are new legal frameworks in Great Britain in respect of age, which Bowes et al. (2008) found to be deeply entwined with the matter of ethnicity. The single Equality and Human Rights Commission (EHRC) has responsibilities for age, sexual orientation, religion and belief and human rights, with new enforcement powers to guarantee equality.

However, the Audit Commission (2004) identified institutional attitudes and behaviours that have historically accompanied thinking about race equality: for example, believing it is not an issue that affects the local community, or that it is one already being addressed by treating everyone the same. It found that many of the barriers to achieving race equality were assumptions that perpetuated the perception of race equality as difficult to address. These assumptions included: race equality was a low priority and there is a lack of resources for the area; confusion about 'mainstreaming', whether services should be separate or for all; difficulty connecting with black and minority ethnic communities; and too many or too few targets for organisations. Its observations may help explain why legal imperatives do not always lead to service or system change.

The potential of legal obligations such as these exposes the ways in which combating elder abuse is not simply a matter for social care services. The wider social policy context has to be considered and this may have the potential to provide greater community cohesion or empowerment of marginalised groups than any direct investment in adult safeguarding. Bowes et al. (2008) revealed that some local community and voluntary organisations felt that they had much to offer in these areas but that the fragility of their funding and the inconsistency of the links with statutory bodies militated against consistent involvement. Not everyone was aware of what needed to be done or indeed 
shared common understandings of problems. The healthcare regulator in England, the Healthcare Commission, has commented on the difficulties of disparate views when trying to effect change in older people's services:

Sustainable change cannot take place unless all partner organisations have a shared view of the direction in which they want to move, and how they plan to get there... A lack of shared direction results in a poor use of resources and a commissioning process that does not encourage change... [and] ... in the provision of an inconsistent and uncoordinated range of services. (Healthcare Commission, 2006: 10)

Policy in the area of adult safeguarding and equalities and diversity may also benefit from explorations of the experiences of racism and its prevention/response among BME older people. Debates in this area have used 'ethnicity' and inequalities but surprisingly have not focused on racism, or only obliquely. This is despite the growing evidence that: 'The different ways in which racism may manifest itself (as interpersonal violence, institutional discrimination, or socioeconomic disadvantage) all have independent detrimental effects on health, regardless of the health indicator used' (Karlsen and Nazroo, 2002: 624). Among older people in the United States, 'Perceived discrimination was associated with increased mortality risk in a general population of older adults. The results suggest that subjective experience of interpersonal mistreatment is toxic in old age' (Barnes et al., 2008: 1241). These studies are building growing evidence of discrimination as an important social determinant of health in later life. No Secrets $(\mathrm{DoH}, 2000)$ included discrimination as a form of abuse and yet this area has been often overlooked in the operational definitions of the term and its nesting within social care and health discourses. The definition in No Secrets was perhaps ahead of its time in suggesting that this behaviour should be encompassed within safeguarding provisions:

discriminatory abuse, including racist, sexist, that based on a person's disability, and other forms of harassment, slurs or similar treatment. (DoH, 2000: para. 2.7)

In the new context of equalities in British social policy, ageism is moving under the spotlight and the interactions of this with racism and abuse/neglect remain uncertain. As Phillips (2007: 99) argued, ethnicity rather than racism has been the 'starting point for people practising care' and it has also been a dominant theme in discussion of BME ageing and responses to this.

This movement may change the nature of debates about elder abuse and race/ethnicity. The literature largely conceptualises BME older people as vulnerable or victims and there are limited depictions of them as active agents in their own and communities' protection or as people implicated in abuse and neglect. This presents a one-sided picture, and ignores a range of other debates about family power dynamics and the situation of people owning or employed in care services. There is little understanding yet of the complexities of 'global care chains' (Hochschild, 2002) in this respect, where care workers and family members are recruited to provide care for more affluent families or older people in their own countries (generally a rural to urban track) or across countries and continents. Concerns in this area about the quality of care and the potential abuse of care workers remain muted. Other types of research, legal cases, inquiries and personal or collective testimony are needed to explore these areas. 
Finally, given the timescale for research in many areas of social policy, policy can change before research is even completed. During the course of the studies considered here, the theme of personalisation and the transformation of social care in England emerged, but too late for the studies considered here. However, both potentially have much to say about the development of choice and control among people using social care services funded by public sector organisations and themselves and their families. First, the NEAS study pointed to the potential for some older couples from all backgrounds to 'manage' on their own terms and not to seek help. Self-directed support may need to work with such couples early on to develop their confidence in making changes and to manage care services, through brokers perhaps, but also to make it clear that seeking help when circumstances are deteriorating may be part of the agreement about the support. Second, new systems of social care need to be more effectively communicated to BME groups who may be particularly uncertain about the workings of self-directed support and the potential risks to communal provision, as care becomes more individualised (Manthorpe and Vallely, 2009). Bowes et al. (2008) revealed the tendency for BME groups to miss out on information and the missed opportunities for training about adult safeguarding to make connections with BME concerns and vice versa, as well as a general lack of confidence about statutory services among BME communities.

\section{Conclusion}

The two studies thus raise a whole raft of questions about how policy and practice in relation to $\mathrm{BME}$ older people being mistreated need to be considered. The voices of the BME communities themselves, as well as the discernible influences on their experiences that originate in wider social and policy processes, suggest a continuing separation of matters of race and ethnicity from mainstream policy and practice thinking. Safeguarding policies lack cultural competence and sensitivity, as have previous service developments. We have argued that there is a need for a broader view when safeguarding is considered, encompassing, for example, the role and capacity of community organisations, the range of pressures that carers may face, and support for the voluntary sector, Contextually, safeguarding policies must be capable of responding to diversity, including ethnic diversity and local variation, as well as age, gender, sexuality, disability and illness. And safeguarding policies need to be tuned into equalities and human rights legislation. Within a system of services advancing rapidly along the personalisation route and attempting increased responsiveness to individuals, the importance and significance of these matters can only increase.

Readers of research studies often try to put them together to make connections and to synthesise findings. This article has undertaken part of this work, noting that policy messages were complementary from two very different studies that were funded across the same time period. It is not common for dissemination to include interactions with other studies, but we would argue that this may be fruitful and may enable researchers to develop findings that are relevant to the needs of policy makers for information.

\section{Acknowledgments and disclaimers}

We thank our colleagues who worked on the studies that we have reviewed; members of the studies' advisory groups and participants; and the reviewers. The views expressed 
in this article are those of the authors alone and should not be interpreted as necessarily representing the views of the Department of Health, Comic Relief, the Big Lottery Fund or Age Concern Scotland.

\section{References}

Audit Commission (2004), The Journey to Race Equality - Delivering Improved Services to Local Communities, London: Audit Commission.

Bajekal, M., Blane, D., Grewal, I., Karlsen, S. and Nazroo, J. (2004), 'Ethnic differences in influences on quality of life at older ages: a quantitative analysis', Ageing and Society, 24, 5, 709-28.

Barnes, L., Mendes de Leon, C., Lewis, T., Bienias, J., Wilson, R. and. Evans, D. (2008), 'Perceived discrimination and mortality in a population-based study of older adults', American Journal of Public Health, 98, 7, 1241-7.

Barrow Cadbury Trust (2007), 'Cities in transition: Britain's increasing plurality', a briefing paper, http://www.bctrust.org.uk/pdf/briefing_paper_on_plurality.

Biggs, S., Phillipson, C. and Kingston, P. (1995), Elder Abuse in Perspective, Buckingham: Open University Press.

Blakemore, K. and Boneham, M. (1994), Age, Race and Ethnicity: A Comparative Approach, Buckingham: Open University Press.

Bowes, A. and Dar, N. (2000), Family Support and Community Care: A Study of South Asian Older People, Edinburgh: Central Research Unit, Scottish Executive.

Bowes, A., Avan, G. and Macintosh, S. B. (2008), They put up with it - what else can they do? Mistreatment of black and minority ethnic older people and the service response, Edinburgh: Age Concern Scotland.

Butt, J. and Mirza, K. (1996), Social Care and Black Communities, London: Race Equality Unit.

Catney, G. and Simpson, L. (2009), 'Settlement area migration in England and Wales: assessing evidence for a social gradient', CCSR Working Paper 2009-02, Cathie Marsh Centre for Census and Survey Research, Manchester.

Department of Health (2000), No Secrets, London: The Stationery Office.

Department of Health (2001), Health Survey for England: The Health of Minority Ethnic Groups '99, London: The Stationery Office.

Department of Health (2007), Putting People First, London: Department of Health.

Department of Health (2008), Safeguarding Adults: A Consultation on the Review of the 'No Secrets' Guidance, London: Department of Health.

Harris, J., Manthorpe, J. and Lakey, S. (2008), Strategic Approaches for Older People from Black and Minority Ethnic Groups, London: Social Care Workforce Research Unit, King's College London.

Harvie, L. (1991), 'Sexual violence and the voluntary sector: Asian women and wife abuse', in A. Bowes and D. Sim (eds.), Demands and Constraints: Ethnic Minorities and Social Services in Scotland, Edinburgh: SCVO.

Healthcare Commission (2006), Living Well in Later Life: Report of the Mid-Point Review of the National Service Framework for Older People, London: Healthcare Commission.

Hochschild, A. R. (2002), 'Love and gold', in B. Ehrenreich and A. R. Hochschild (eds.), Global Woman: Nannies, Maids, and Sex Workers in the New Economy, New York: Metropolitan Books.

House of Commons (2004), Health Committee: Elder Abuse Second Report of Session 2003-04, Volume I, London: House of Commons.

Iliffe, S. and Manthorpe, J. (2004), 'Ethnicity and dementia: from category fallacy to patient centred care', Aging and Mental Health, 28, 4, 283-92.

Karlsen, S. and Nazroo, J. (2002), 'Relation between racial discrimination, social class, and health among ethnic minority groups', American Journal of Public Health, 92, 4, 624-31.

Katbamna, S. and Matthews, R. (2006), Ageing and Ethnicity in England: A Demographic Profile of BME Older People in England, London: Age Concern. 
Lowdell, C., Evandrou, M., Bardsley, M., Morgan, M. and Soljak, M. (2000), Health of Ethnic Minority Elders in London, London: East London and The City Health Authority.

Manthorpe, J. et al. (2005), 'Select questions: considering the issues raised by a Parliamentary Select Committee into elder abuse', Journal of Adult Protection, 7, 3, 19-32.

Manthorpe, J. et al. (2008), 'Number and nuances: the implications for adult protection co-ordinators and committees of the UK national prevalence study of abuse and neglect of older people', Journal of Adult Protection, 10, 1, 13-23.

Manthorpe, J. and Vallely, S. (2009), Building Choices 2, London: Housing 21.

McCreadie, C. et al. (2006), 'First steps: the UK national prevalence study of the mistreatment and abuse of older people', Journal of Adult Protection, 8, 3, 4-11.

Moriarty, J. and Butt, J. (2004), 'Inequalities in quality of life among older people from different ethnic groups', Ageing and Society, 24, 5, 729-53.

Mowlam, A., Tennant, R., Dixon, J. and McCreadie, C. (2007), Mistreatment and Abuse of Older People: Qualitative Findings, London: Comic Relief and Department of Health.

Office of National Statistics (2002), Social Focus in Brief: Ethnicity, London: Office for National Statistics.

O'Keefe, M. et al. (2007), UK Study of Abuse and Neglect of Older People: Prevalence Survey Report, London: National Centre for Social Research.

Patterson, M. and Malley-Morrison, K. (2006), 'A cognitive-ecological approach to elder abuse in five cultures: human rights and education', Educational Gerontology, 32, 1, 73-82.

Phillips, J. (2007), Care, Cambridge: Polity.

PRIAE (Policy Research Institute for Ageing and Ethnicity) (2005), 'Black and minority elders in the UK: health and social care research findings', PRIAE, Leeds, www.priae.org/docs/ MEC\%20UK\%20\%20Summary\%20Findings.pdf

Samad, Y. and Eade, J. (2003), 'Community perceptions of forced marriage', http://www.fco.gov. uk/Files/kfile/clureport.pdf

Scott, H. (ed.) (1998), Speaking Out: Elder Abuse and Minority Ethnic Elders, edited papers of the first national UK conference, London: Action on Elder Abuse and Neighbourhood Care Project (Newham) Ltd.

Secretary of State for Health (2004), 'The Government's response to the recommendations and conclusions of The Health Select Committee's Inquiry into Elder Abuse', Department of Health, London, Cm 6270.

Slater, P. and Eastman, M. (eds.) (1999), Elder Abuse: Critical Issues in Policy and Practice, London: Age Concern England.

Tsukada, N., Saito, Y. and Tatara, T. (2001), 'Japanese older people's perceptions of "elder abuse"', Journal of Elder Abuse and Neglect, 13, 1, 71-89.

Watson, Y. (2008), 'The cure for prevention is cultural sensitivity', Ethnicity and Inequalities in Health and Social Care, 1, 2, 8-10.

Yan, E. and Tang, C. S. (2003), 'Proclivity to elder abuse: a community study on Hong Kong Chinese', Journal of Interpersonal Violence, 18, 9, 999-1017. 